\title{
Idiopathic and normal lateral lumbar curves: muscle effects interpreted by 12th rib length asymmetry with pathomechanic implications for lumbar idiopathic scoliosis
}

Theodoros B. Grivas ${ }^{1 *}$, R. Geoffrey Burwell ${ }^{2}$, Vasileios Kechagias ${ }^{1}$, Christina Mazioti ${ }^{1}$, Apostolos Fountas ${ }^{1}$, Dimitra Kolovou ${ }^{3}$ and Evangelos Christodoulou ${ }^{4}$

From 12th International Conference on Conservative Management of Spinal Deformities - SOSORT 2015 Annual Meeting Katowice, Poland. 7-9 May 2015

\begin{abstract}
Background: The historical view of scoliosis as a primary rotation deformity led to debate about the pathomechanic role of paravertebral muscles; particularly multifidus, thought by some to be scoliogenic, counteracting, uncertain, or unimportant. Here, we address lateral lumbar curves (LLC) and suggest a pathomechanic role for quadrates lumborum, (QL) in the light of a new finding, namely of 12th rib bilateral length asymmetry associated with idiopathic and small non-scoliosis LLC.

Methods: Group 1: The postero-anterior spinal radiographs of 14 children (girls 9, boys 5) aged 9-18, median age 13 years, with right lumbar idiopathic scoliosis (IS) and right LLC less that $10^{\circ}$, were studied. The mean Cobb angle was $12^{\circ}$ (range $5-22^{\circ}$ ). Group 2: In 28 children (girls 17 , boys 11 ) with straight spines, postero-anterior spinal radiographs were evaluated similarly to the children with the LLC, aged 8-17, median age 13 years. The ratio of the right/left 12th rib lengths and it's reliability was calculated. The difference of the ratio between the two groups was tested; and the correlation between the ratio and the Cobb angle estimated. Statistical analysis was done using the SPSS package.

Results: The ratio's reliability study showed intra-observer $+/-0,036$ and the inter-observer error $+/-0,042$ respectively in terms of $95 \%$ confidence limit of the error of measurements. The 12th rib was longer on the side of the curve convexity in 12 children with LLC and equal in two patients with lumbar scoliosis. The 12th rib ratios of the children with lumbar curve were statistically significantly greater than in those with straight spines. The correlation of the 12th rib ratio with Cobb angle was statistically significant. The 12th thoracic vertebrae show no axial rotation (or minimal) in the LLC and no rotation in the straight spine group.

(Continued on next page)
\end{abstract}

\footnotetext{
* Correspondence: tgri69@otenet.gr

'Department of Orthopaedics and Traumatology, "Tzaneio" General Hospital,

Tzani and Afendouli 1, Piraeus 18536, Greece

Full list of author information is available at the end of the article
} 
(Continued from previous page)

Conclusions: It is not possible, at present, to determine whether the 12th convex rib lengthening is congenitally lengthened, induced mechanically, or both. Several small muscles are attached to the 12th ribs. We focus attention here on the largest of these muscles namely, QL. It has attachments to the pelvis, 12th ribs and transverse processes of lumbar vertebrae as origins and as insertions. Given increased muscle activity on the lumbar curve convexity and similar to the interpretations of earlier workers outlined above, we suggest two hypotheses, relatively increased activity of the right QL muscle causes the LLCs (first hypothesis); or counteracts the lumbar curvature as part of the body's attempt to compensate for the curvature (second hypothesis). These hypotheses may be tested by electrical stimulation studies of QL muscles in subjects with lumbar IS by revealing respectively curve worsening or correction. We suggest that one mechanism leading to relatively increased length of the right 12 ribs is mechanotransduction in accordance with Wolff's and Pauwels Laws.

\section{Background}

The historical view of scoliosis as a primary rotation deformity [1] led to debate about the pathomechanic role of paravertebral muscles; particularly multifidus, thought by some to be scoliogenic [2-4], counteracting $[5,6]$, uncertain [7], or unimportant [8]. Here, we address LLC and suggest a pathomechanic role for quadrates lumborum, (QL) in the light of a new finding, namely of 12th rib bilateral length asymmetry associated with idiopathic and small non-scoliosis LLC.

\section{Methods}

\section{Ethical issues}

Written consent was obtained from the patients or their relatives for publication of this study. IRB approval has been obtained, (21-5-2015 min of 42nd meeting of the "Tzaneio" General Hospital Scientific Council), for the implementation of this research.

\section{Definitions}

We define Lateral Lumbar Curve (LLC) in the text as all the lumbar curves with a Cobb angle less than $10^{\circ}$. When LLC is $10^{\circ}$ or more it is a scoliosis. The children with LLC less than $10^{\circ}$ of Cobb angle are not characterized as having scoliosis.

\section{The examinees}

We include subjects with scoliosis having LLC in our data base during the last 5 years, when this Scoliosis Outpatient Department (UPD) was started upon the appointment in the hospital of the first author. The older patients in the samples were included as part of all the registered children and adolescents with LLC in our scoliosis UPD.

A right LLC deemed of primary interest because it was our observation that in LLC the 12th pair of ribs did not have equal length. We included right lumbar only

Table 1 Details for children in group one

\begin{tabular}{|c|c|c|c|c|c|c|c|c|}
\hline Number & $\begin{array}{l}\text { Male(M) } \\
\text { Female (F) }\end{array}$ & $\begin{array}{l}\text { Age in } \\
\text { years }\end{array}$ & $\begin{array}{l}\text { Right 12th rib } \\
\text { length in } \mathrm{cm}\end{array}$ & $\begin{array}{l}\text { Left 12th rib } \\
\text { length in } \mathrm{cm}\end{array}$ & $\begin{array}{l}\text { ratio right/left } \\
\text { 12th rib lengths }\end{array}$ & $\begin{array}{l}\text { ratio left/right } \\
\text { 12th rib lengths }\end{array}$ & Curve & $\begin{array}{l}\text { Lumbar } \\
\text { Cobb angle }\end{array}$ \\
\hline 1 & $\mathrm{~F}$ & 18 & 7,5 & 7,2 & 1,04 & 0,96 & RIGHT T11-L4= 5 & 5 \\
\hline 2 & $\mathrm{~F}$ & 13 & 10,7 & 10,6 & 1,01 & 0,99 & RIGHT T11-L4 = 5 & 5 \\
\hline 3 & M & 10 & 6,8 & 6,8 & 1,00 & 1,00 & RIGHT L1-L4 = 6 & 6 \\
\hline 4 & $\mathrm{~F}$ & 12 & 9,5 & 9,4 & 1,01 & 0,99 & RIGHT T11-L4 = 8 & 8 \\
\hline 5 & $\mathrm{~F}$ & 10 & 7 & 6,8 & 1,03 & 0,97 & RIGHT T12-L3 = 9 & 9 \\
\hline 6 & $\mathrm{~F}$ & 14 & 10,5 & 10,5 & 1,00 & 1,00 & RIGHT T12-L4 = 9 & 9 \\
\hline 7 & M & 9 & 7,1 & 6 & 1,18 & 0,85 & RIGHT T12-L4 = 10 & 10 \\
\hline 8 & M & 11 & 8,4 & 8 & 1,05 & 0,95 & RIGHT L1-L4 = 13 & 13 \\
\hline 9 & M & 15 & 6,2 & 5,6 & 1,11 & 0,90 & RIGHT T10-L3 = 15 & 15 \\
\hline 10 & $\mathrm{~F}$ & 13 & 8,1 & 7 & 1,16 & 0,86 & RIGHT T10-L3 = 15 & 15 \\
\hline 11 & $\mathrm{~F}$ & 13 & 7,4 & 6,8 & 1,09 & 0,92 & RIGHT T12-L4 = 15 & 15 \\
\hline 12 & M & 15 & 6,2 & 5,8 & 1,07 & 0,94 & RIGHT T10-L4 = 19 & 17 \\
\hline 13 & $\mathrm{~F}$ & 12 & 9,4 & 8,8 & 1,07 & 0,94 & RIGHT T7-L2 = 21 & 18 \\
\hline 14 & $\mathrm{~F}$ & 15 & 10,6 & 9,4 & 1,13 & 0,89 & RIGHT T12-L4 = 22 & 22 \\
\hline
\end{tabular}


because the number of children with left lumbar curves we have in our registry is very small to analyse.

Two groups of children were formed. The posteroanterior (P-A) spinal radiographs of these two groups of examinees were assessed.

Group 1: The P-A spinal radiographs of 14 children (girls 9, boys 5) with right lumbar idiopathic scoliosis (IS) and right LLC less that $10^{\circ}$, were studied, aged 9-18, median age 13 years. The mean Cobb angle of all these children was $12^{\circ}$ (range $5-22^{\circ}$ ), Table 1 . No neurological signs were found on clinical examination in all children suffering lumbar idiopathic scoliosis. The group 1 is smaller than group 2 because both the history of our scoliosis UPD is short and the incidence of LLC is very small as well.
Group 2: In 28 children (girls 17, boys 11) with straight spines, the P-A spinal radiographs were evaluated similarly to the children with the LLC, aged 8-17, median age 13 years, Table 2.

There was no pelvic tilt in both groups.

\section{The measurements}

The length in $\mathrm{cm}$ from its head to the lateral end point of each of the right and the left 12th rib was measured in the two groups of examinees' P-A spinal radiographs, Figs. 1 and 2. The ratio of the right/left 12th rib lengths and its reliability calculated. We also assess the existence of vertebral rotation, observing the symmetry of the pedicles. If 12 th vertebra is rotated then the curve could be thoracolumbar.

Table 2 Details for children in group two

\begin{tabular}{|c|c|c|c|c|c|c|c|}
\hline Number & $\begin{array}{l}\text { Male(M) } \\
\text { Female (F) }\end{array}$ & $\begin{array}{l}\text { Age in } \\
\text { years }\end{array}$ & $\begin{array}{l}\text { Right 12th rib } \\
\text { length in } \mathrm{cm}\end{array}$ & $\begin{array}{l}\text { Left 12th rib } \\
\text { length in } \mathrm{cm}\end{array}$ & $\begin{array}{l}\text { ratio right/left } \\
12 \text { th rib lengths }\end{array}$ & $\begin{array}{l}\text { ratio left/right } \\
12 \text { th rib lengths }\end{array}$ & Lumbar spine \\
\hline 1 & $\mathrm{~F}$ & 9 & 8,7 & 9,1 & 0,96 & 1,05 & STRAIGHT \\
\hline 2 & $\mathrm{~F}$ & 14 & 10,5 & 10,8 & 0,97 & 1,03 & STRAIGHT \\
\hline 3 & M & 12 & 10,7 & 10,7 & 1,00 & 1,00 & STRAIGHT \\
\hline 4 & M & 12 & 8,9 & 9,5 & 0,94 & 1,07 & STRAIGHT \\
\hline 5 & $\mathrm{~F}$ & 12 & 10 & 10,4 & 0,96 & 1,04 & STRAIGHT \\
\hline 6 & M & 12 & 9,1 & 9 & 1,01 & 0,99 & STRAIGHT \\
\hline 7 & $\mathrm{~F}$ & 12 & 3,7 & 4,1 & 0,90 & 1,11 & STRAIGHT \\
\hline 8 & $\mathrm{~F}$ & 13 & 10,6 & 11 & 0,96 & 1,04 & STRAIGHT \\
\hline 9 & $\mathrm{~F}$ & 13 & 4,2 & 4,4 & 0,95 & 1,05 & STRAIGHT \\
\hline 10 & M & 13 & 5,4 & 5,2 & 1,04 & 0,96 & STRAIGHT \\
\hline 11 & M & 14 & 9 & 8,4 & 1,07 & 0,93 & STRAIGHT \\
\hline 12 & $\mathrm{~F}$ & 13 & 8,4 & 8,1 & 1,04 & 0,96 & STRAIGHT \\
\hline 13 & $\mathrm{~F}$ & 14 & 10,4 & 10,3 & 1,01 & 0,99 & STRAIGHT \\
\hline 14 & $\mathrm{~F}$ & 15 & 9,8 & 10,3 & 0,95 & 1,05 & STRAIGHT \\
\hline 15 & $\mathrm{~F}$ & 10 & 3,6 & 3,7 & 0,97 & 1,03 & STRAIGHT \\
\hline 16 & M & 17 & 6,1 & 6 & 1,02 & 0,98 & STRAIGHT \\
\hline 17 & $\mathrm{~F}$ & 14 & 10,8 & 10,7 & 1,01 & 0,99 & STRAIGHT \\
\hline 18 & $\mathrm{~F}$ & 14 & 5,1 & 4,9 & 1,04 & 0,96 & STRAIGHT \\
\hline 19 & M & 10 & 7,8 & 7,5 & 1,04 & 0,96 & STRAIGHT \\
\hline 20 & M & 8 & 3,3 & 3,5 & 0,94 & 1,06 & STRAIGHT \\
\hline 21 & $\mathrm{~F}$ & 14 & 7,9 & 8,2 & 0,96 & 1,04 & STRAIGHT \\
\hline 22 & $\mathrm{~F}$ & 14 & 11,1 & 10,7 & 1,04 & 0,96 & STRAIGHT \\
\hline 23 & $\mathrm{~F}$ & 14 & 7,4 & 6,7 & 1,10 & 0,91 & STRAIGHT \\
\hline 24 & M & 15 & 10,1 & 10,2 & 0,99 & 1,01 & STRAIGHT \\
\hline 25 & $\mathrm{~F}$ & 11 & 5,1 & 5,1 & 1,00 & 1,00 & STRAIGHT \\
\hline 26 & M & 14 & 8,4 & 8,1 & 1,04 & 0,96 & STRAIGHT \\
\hline 27 & M & 13 & 6,1 & 5,8 & 1,05 & 0,95 & STRAIGHT \\
\hline 28 & $\mathrm{~F}$ & 12 & 4,7 & 4,8 & 0,98 & 1,02 & STRAIGHT \\
\hline
\end{tabular}




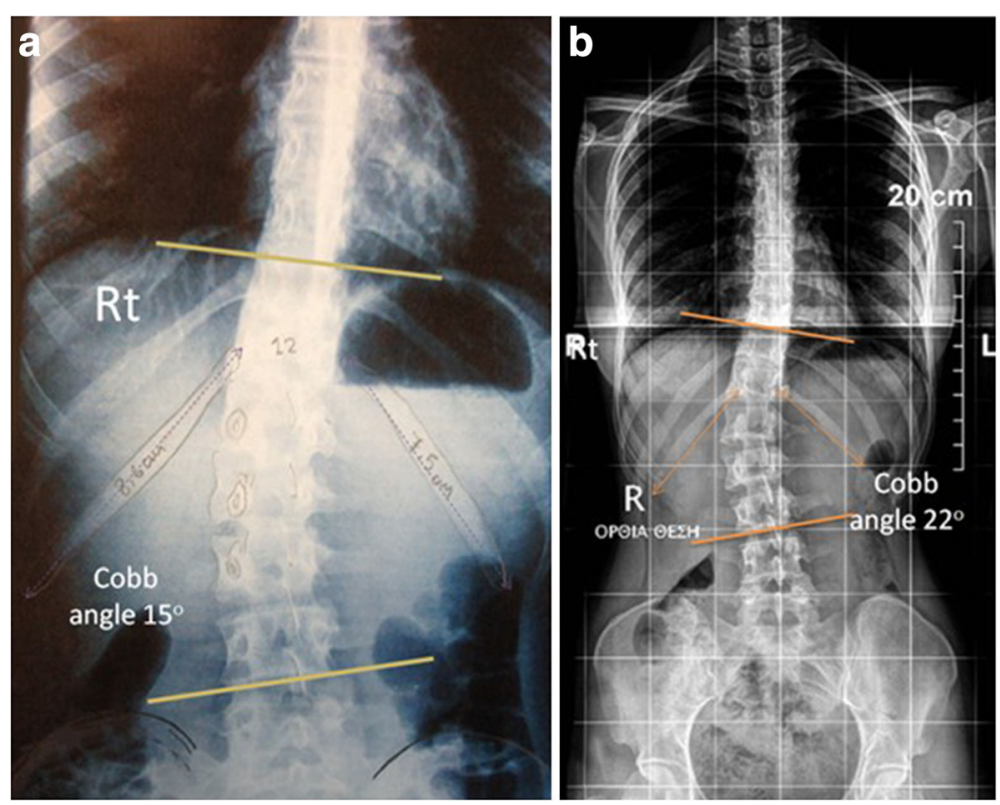

Fig. 1 a. Right lumbar idiopathic curve $15^{\circ}$ of Cobb angle, the right 12 th rib is longer, similarly in figure $\mathbf{b}$, in a right lumbar idiopathic curve $22^{\circ}$ of Cobb angle, the right 12th rib is longer

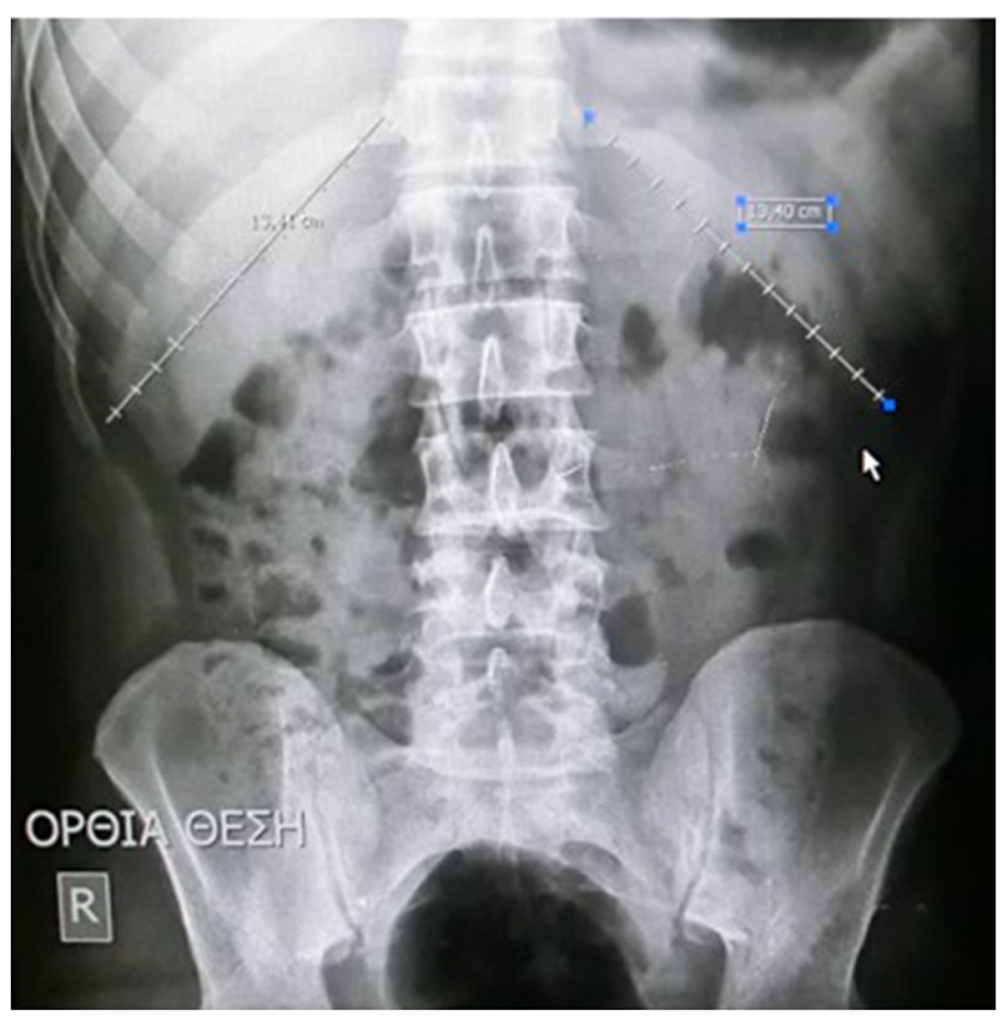

Fig. 2 In this straight spine, the right 12th rib measures $13,41 \mathrm{~cm}$ while the left $13,40 \mathrm{~cm}$ respectively 


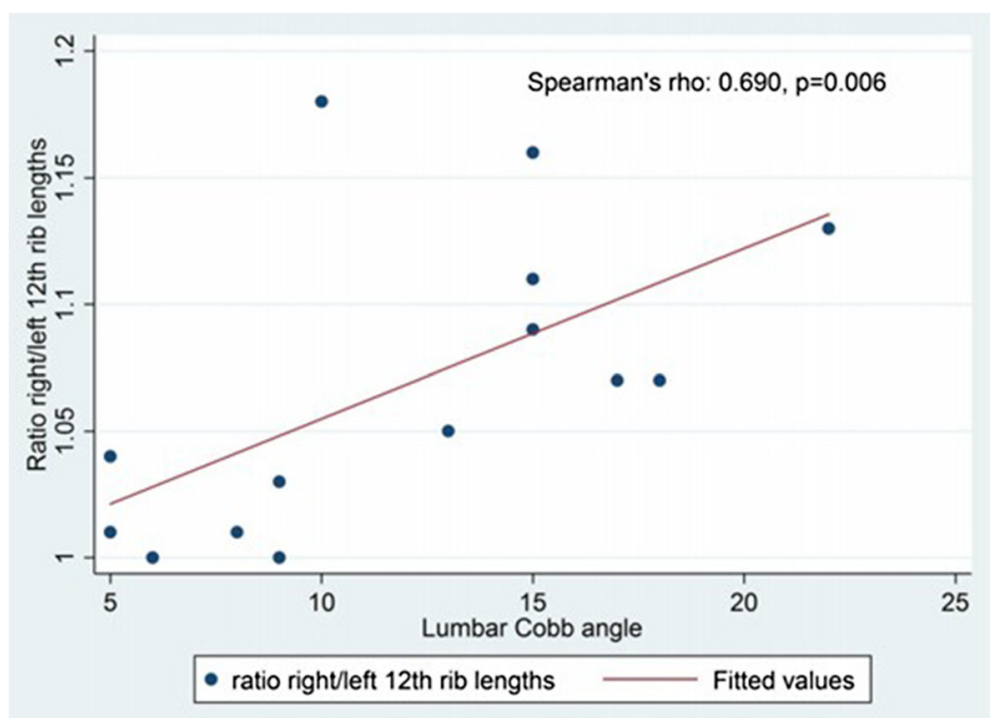

Fig. 3 Scatter plot of lumbar Cobb angle by ratio right/left rib lengths. The correlation was statistically significant, $(r=0,690, p=0,006)$

The statistical analysis

The difference of the ratio between the two groups was tested (Mann-Whitney) and the correlation between the ratio and the Cobb angle estimated (Spearman's rho). The statistical analysis was done using the SPSS package v22.

\section{Study design}

This is a case-control study and of level of evidence III.

\section{Results}

The ratio reliability study showed intra-observer $+/-0,036$ and the inter-observer error $+/-0,042$ respectively in terms of $95 \%$ confidence limit of the error of measurements.
The 12th rib was longer on the side of the curve convexity in 12 children with LLC and equal in two patients with lumbar scoliosis.

The 12th rib ratios of the children with lumbar curves were statistically significantly greater than in those with straight spines (Mann-Whitney $U=71,000$, $p<0,001)$.

The correlation of the twelfth rib ratio with Cobb angle was statistically significant, (Spearman's rho = $0,690, p=0,006)$, Fig. 3 .

The 12th thoracic vertebrae show no axial rotation (or minimal) in the LLC and no rotation on straight spine groups.

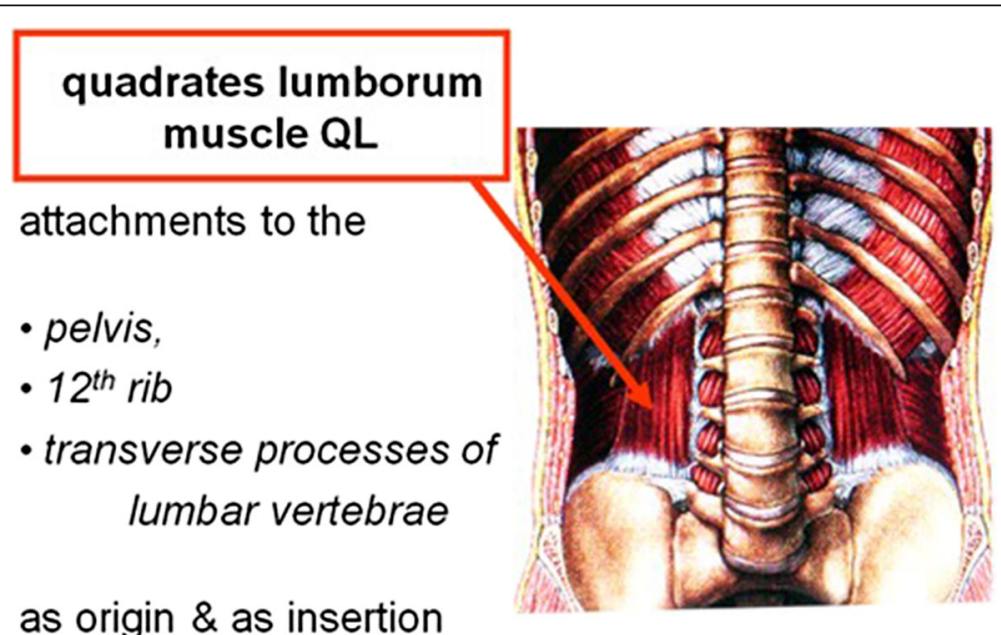

Fig. 4 Quadrates lumborum attachments 


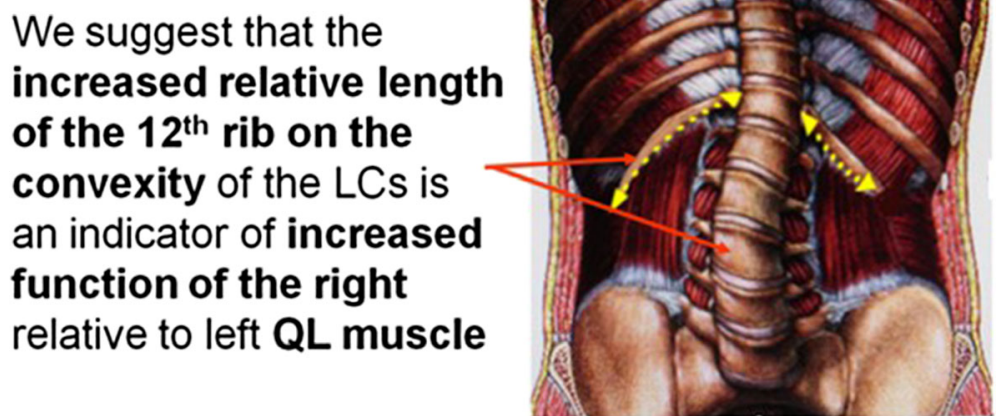

Fig. 5 Our hypothesis on the increased relative length of the 12th rib on the convexity of right lumbar idiopathic scoliotic curves

\section{Discussion and conclusions}

It is not possible, at present, to determine whether the 12th convex rib lengthening is congenitally lengthened, induced mechanically, or both. One question could be posed on whether the asymmetry in the rib length preceded the curves (possibly causal) or developed as a reaction to the increased demand. Answering this question it is stated that our data are cross-sectional, so we can only comment on data we do have (the radiographs obtained at a certain age). We do not have longitudinal data to address this question.

Several small muscles are attached to the 12th ribs. Attachments to the 12th ribs include diaphragm, quadrates lumborum, Fig. 4, internal and external intercostals, serratus posterior inferior, short and long rib elevators, external oblique abdominal, internal oblique abdominal, transversus abdominis, iliocostalis and longissimus thoracis.

We focus attention here on the largest of these muscles namely, QL. The largest muscles, attached to the 12th ribs namely quadrates lumborum, are likely to exert the greatest forces on the 12th ribs.

QL has attachments to the pelvis, 12th ribs and transverse processes of lumbar vertebrae as origins and as insertions.

Riddle and Roaf [2], using electromyography in paralytic and idiopathic thoracic and paralytic lumbar scoliosis, reported the spinal muscles were significantly stronger on the convex side at the apex of the curve. Given the increased muscle activity on the lumbar curve convexity and similar to the interpretations of earlier workers outlined above in the Background section, we suggest two hypotheses, relatively increased activity of the right $\mathrm{QL}$ muscle causes the LLCs (first hypothesis); or counteracts the lumbar curvature as part of the body's attempt to compensate for the curvature (second hypothesis). These hypotheses may be tested by electrical stimulation studies of QL muscles in subjects with lumbar IS by revealing respectively curve worsening or correction. We suggest that one mechanism leading to relatively increased length of the right 12 ribs is mechanotransduction [9] in accordance with Wolff's and Pauwels Laws, Fig. 5.

Wolff's law is a theory developed by the German anatomist and surgeon Julius Wolff (1836-1902) in the 19th century that states that bone in a healthy person or animal will adapt to the loads under which it is placed. If loading on a particular bone increases, the bone will remodel itself over time to become stronger to resist that sort of loading, [10,11].

Pauwels' law states that intermittent pressure within the physiological limits of stress and strain stimulates the growth plates of a healthy bone, $[12,13]$.

The concept of this short paper was in brief published [14].

\section{Abbreviations}

IS: Idiopathic scoliosis; QL: Quadrates lumborum; UPD: Outpatient department; LLC: Lateral lumbar curves; SS: Statistically significantly

\section{Acknowledgements}

We would like to thank Dr. Constantinos Mihas for his valuable contribution to the statistical analysis.

\section{Declarations}

This article has been published as part of Scoliosis and Spinal Disorders Volume 11 Supplement 2, 2016. Research into Conservative Management of Spinal Deformities: Short Articles from the SOSORT 2015 Meeting. The full contents of the supplement are available online http://scoliosisjournal.biomedcentral.com/articles/supplements/volume11-supplement-2.

\section{Availability of data and materials}

Readily the data and materials described in the manuscript (table 1 and 2) will be available, but with anonymity.

\section{Authors' contributions}

TBG: Made the observation of the longer convex twelfth rib in right lumbar idiopathic scoliosis, searched the literature, interpreted the findings, drafted the text did the statistical analysis and designed the photographs. RGB searched the literature, drafted the text and interpreted the findings, VK, CM, AF, DK, EC,helped in the data aquisition. All authors contributed their professional skills to the inclusions of the text. All authors have read and approved the final manuscript.

Competing interests

The authors declare that they have no competing interests. 


\section{Consent for publication}

Written consent was obtained from the patients or their relatives for publication of the collected data, but with anonymity.

\section{Ethics approval and consent to participate}

Written consent was obtained from the patients or their relatives for participation in this study. IRB approval has been obtained, (21-5-2015 minutes of $42^{\text {nd }}$ meeting of the "Tzaneio" General Hospital Scientific Council), for the implementation of this research.

\section{Author details}

'Department of Orthopaedics and Traumatology, "Tzaneio" General Hospital, Tzani and Afendouli 1, Piraeus 18536, Greece. ${ }^{2}$ Centre for Spinal Studies and Surgery, Nottingham University Hospitals NHS Trust, Queen's Medical Centre Campus, Nottingham, UK. ${ }^{3}$ Department of Radiology, "Tzaneio" General Hospital, Tzani and Afendouli 1 st, Piraeus 18536, Greece. ${ }^{4}$ Asklepios Klinik Lindenlohe, Schwandorf, Germany.

\section{Published: 14 October 2016}

\section{References}

1. Roaf R. 1958 Rotation movements of the spine with special reference to scoliosis. J Bone Joint Surg Br. 1958;40-B(2):312-32.

2. Riddle HFV, Roaf R. Muscle imbalance in the causation of scoliosis. Lancet, 1. 1955;268(6877):1245-7. PMID:14382561.

3. Fidler MW, Jowett RL, Troup JDG. Histochemical study of the function of multifidus in scoliosis. In: Zorab PA, editor. Scoliosis and Muscle. London: William Heinemann Medical Books Ltd; 1974. p. 184-92.

4. Fidler MW, Jowett RL. Muscle imbalance in the aetiology of scoliosis. J Bone Joint Surg Br. 1976;58(2):200-1.

5. Zuk T. The role of spinal and abdominal muscles in the pathogenesis of scoliosis. Journal of Bone and Joint Surgery. 1962;44-B:102-5.

6. Schmitt O. Electrical Stimulation of intercostal muscles in idiopathic scoliosis. Proceedings of the Third Meeting of ISAO, Motor Prosthesis and Bone Stimulation, Artificial Organs. 1981;5(Suppl):589-93.

7. Roaf R. The intercostal muscles and conditioned reflexes in the control of spinal posture. Proc R Soc Med. 1976;69(3):177-8. PMID:1265009, PMCID: PMC1864150.

8. Millner PA, Dickson RA. Idiopathic scoliosis: biomechanics and biology. Eur Spine J. 1996;5(6):362-73.

9. Stokes IA, Burwell RG, Dangerfield PH. IBSE. Biomechanical spinal growth modulation and progressive adolescent scoliosis - a test of the 'vicious cycle' pathogenetic hypothesis: summary of an electronic focus group debate of the IBSE. Scoliosis. 2006;18(1):16.

10. Wolff J. The Law of Bone Remodelling. In: Maquet P, Furlong R, editors. Berlin: Springer-Verlag; 1986.

11. Wolff J. The Classic. Concerning the interrelationship between form and function of the individual parts of the organism. Clin Orthop. 1988;228:2-11.

12. Golding JSR. The mechanical factors which influence bone growth. Eur J Clin Nutr. 1994:48 Suppl 1:S178-85.

13. Mau H. Specifizierung der korrespondierenden Wachstums-Gesetze von Hueter-Volkmann und Pauwels (Wachstumde-formitäten) und ihre Beziehung zu den Belasungsde-förmitäten. Z Orthop. 1984;122:293-8.

14 Grivas TB, Burwell RG, Kechagias V, Mazioti C, Fundas A, Kolovou D, Christodoulou E. Idiopathic and normal lateral lumbar curves: muscle effects interpreted by 12 th rib length asymmetry with pathomechanic implications for lumbar idiopathic scoliosis. Eur Spine J. 2015;24(11): 2614-707.

\section{Submit your next manuscript to BioMed Central and we will help you at every step:}

- We accept pre-submission inquiries

- Our selector tool helps you to find the most relevant journal

- We provide round the clock customer support

- Convenient online submission

- Thorough peer review

- Inclusion in PubMed and all major indexing services

- Maximum visibility for your research

Submit your manuscript at www.biomedcentral.com/submit 